\title{
ADMINISTRAÇÃO PÚBLICA: POSSIBILIDADES E DESAFIOS A PARTIR DOS MODELOS DE GESTÃO
}

\section{ARTIGO ORIGINAL}

FREITAS, Paulo Victor de Oliveira ${ }^{1}$

FREITAS, Paulo Victor de Oliveira. Administração Pública: Possibilidades e desafios a partir dos modelos de gestão. Revista Científica Multidisciplinar Núcleo do Conhecimento. Ano 05, Ed. 12, Vol. 19, pp. 60-69. Dezembro de 2020. ISSN: 24480959 , Link de

acesso: https://www.nucleodoconhecimento.com.br/administracao/modelos-degestao

\section{RESUMO}

Este trabalho tem como objetivo analisar as evoluções históricas relacionadas à administração pública brasileira, enfatizando seus benefícios e dificuldades de acordo com o contexto histórico e social de cada gestão. Diante da necessidade de exigir dos setores públicos um aperfeiçoamento nos seus serviços a fim de que atendam de forma satisfatória a sociedade. Com o passar dos anos foram surgindo novos modelos de gestão na administração pública. A partir de pesquisa bibliográfica, verificam-se pelo menos três modelos: administração pública patrimonialista, pautada pelo clientelismo; burocrática, com uma visão mais formal e procedimental e a gerencial que está voltada para a satisfação do cidadão. Atualmente, o modelo gerencial é o mais utilizado em todos os órgãos da administração pública, no entanto foi possível constatar que há readaptação de alguns valores do patrimonialista e burocrático e que ainda estão em execução nos dias de hoje. Assim sendo, conclui-se que não há uma padronização na gestão nos órgãos públicos, porém é de extrema importância o

\footnotetext{
1 Pós-graduado em Gestão da Administração Pública pela Faculdade IPPEO; Pósgraduado em Gestão de Processos de Negócios pela Faculdade IPPEO; Graduado em Administração pelo Centro Universitário Augusto Motta.
} 
estudo dos modelos acima para o entendimento do cenário atual e na conscientização para que os serviços públicos favoreçam ao cidadão, através da busca constante pela ética, eficiência e legitimidade.

Palavras-chave: administração pública, modelos de gestão, gestão patrimonialista, gestão burocrática, gestão gerencial.

\section{INTRODUÇÃO}

Constantes transformações no Estado e na sociedade têm sido marcadas nas últimas décadas. Estudos voltados para a administração pública buscam compreender de que forma estas transformações impactaram no funcionamento e nas ações governamentais a partir de uma perspectiva econômica e tecnológica quanto a de caráter social.

Sem dúvida alguma, ao longo do tempo, a administração pública desenvolveu-se de forma exponencial e um importante segmento da ciência da Administração, buscando a satisfação das necessidades coletivas básicas.

A fim de construir uma gestão pública mais dinâmica, fazem-se necessárias iniciativas do governo que aprimorem os serviços prestados à população. Em virtude das altas taxas tributárias e a insatisfação pelos escândalos de corrupção, há uma maior cobrança dos cidadãos com relação à transparência e utilização dos recursos públicos, que tem sido fundamental para este processo de evolução da gestão pública. Segundo a Constituição Federal, a administração pública deve atender princípios expressos: "a administração pública direta e indireta de qualquer um dos Poderes da União, dos Estados, do Distrito Federal e dos Municípios obedecerá aos princípios de legalidade, impessoalidade, moralidade, publicidade e eficiência." (BRASIL, 1988, Art.37).

No Brasil, a gestão pública obteve três modelos de governo, sendo estes: patrimonialista, burocrática e gerencial. Partindo desse pressuposto, indaga-se o 
seguinte questionamento: Qual a forma de governar mais eficaz e eficiente no oferecimento dos serviços essenciais à população?

Visando aprofundar os estudos sobre o tema, o presente artigo tem o objetivo de resgatar historicamente as evoluções das gestões até os dias de hoje, analisando a partir da perspectiva de organização pública, mapeando suas diretrizes e princípios.

A partir daí, almeja-se compreender sobre a importância do conhecimento para o entendimento da gestão e também instrução para gestores do setor público, tendo sua relevância científica e social à Administração Pública do Brasil, a fim de valorizar a ação humana em sua prática.

\section{EVOLUÇÃO NOS MODELOS DE GESTÃO PÚBLICA}

Durante muitos anos, a história do Brasil foi marcada pela dinastia política e poder. Segundo Torres (2004, p.45), "a sociedade brasileira foi criada e desenvolvida sob o controle atento de um Estado centralizador, onipotente e espoliado por uma elite patrimonial que persiste por séculos".

Com o passar dos anos a administração pública foi passando por diversas transformações e diante dos anseios dos cidadãos foram necessárias novas adaptações a partir das evoluções das estruturas administrativas.

Para uma gestão pública eficiente, vai muito além de cuidar dos recursos estatais e do patrimônio, a fim de reconhecer e se situar diante de suas práticas irá se aprofundar um pouco mais sobre cada modelo de gestão.

\subsection{PRÁTICAS PATRIMONIALISTAS DE GESTÃO}

O patrimonialismo foi implantado no Brasil no período colonial a partir da sua Independência, esse modo de gestão se iniciou a partir de uma dominação tradicional, onde os portugueses chegaram tendo como intuito dominar e tomar posse de todo território e junto com isso exercer poder e domínio sobre tudo que pudesse ser governado. 
O modelo de governantes que se moldou a partir de tais costumes ficou caracterizado pela cordialidade, que trata de situações que deveriam ser de interesse geral e caráter impessoal da mesma maneira como trataria de seus problemas pessoais, mas sempre mantendo as relações de poder intactas, na qual os mesmo grupos sempre se encontram acima dos demais (HOLANDA, 1963, p.147).

Deste modo, o patrimonialismo é um modo de gestão pública onde o público e o privado se confundem, pois o Estado é composto por reis e monarcas que exercem o poder soberano. A autoridade e o controle sobre todo um território encontram-se alojados somente nas mãos de seu governante e nas pessoas escolhidas por ele, deste modo, cargos públicos e administrativos são concedidos a familiares e amigos.

Uma das principais características do patrimonialismo é a gestão por um conjunto de membros, na maioria das vezes que fazem parte de uma mesma família e amigos próximos, exercem poder sobre toda uma sociedade, não é eficaz, muito menos igualitário, tendo em vista que as necessidades supridas são em grande parte advindas de interesses pessoais e não coletivos.

Sendo assim, o nepotismo e o uso de recursos públicos eram considerados normas na administração patrimonialista. Além disso, nesse modelo de gestão destaca-se a corrupção, escolha de empregados a partir do círculo pessoal do senhor, falta de especialização profissional e uma dicotomia burocrática entre empresas privadas e os serviços públicos.

Em substituição aos regimes autoritários de poder exercidos na gestão patrimonial e partindo da necessidade de conseguir controlar as ações do governo, surge a administração burocrática.

\subsection{PRÁTICAS BUROCRÁTICAS DE GESTÃO}

A fim de realizar um modelo de gestão com fiscalizações mais rigorosas, diminuir problemas como o favorecimento e o apadrinhamento de pessoas da mesma família no poder, a separação entre o público e o privado, o incentivo ao mercado trabalhista 
e o poder burocrático, iniciou-se a implementação da gestão burocrática, após anos de patrimonialismo.

Este modo de gestão, que surge na Era Vargas, em um período em que o avanço do capitalismo era de extrema necessidade para o desenvolvimento do país e a administração pública sofre grande influência um processo de racionalização e intervindo pesadamente no setor produtivo de bens e serviços. Assim sendo, ocorre uma diferenciação do político e do administrador público:

Começa a tomar forma assim à administração burocrática moderna, racional legal (nos termos de Weber); surge a organização burocrática, baseada na centralização das decisões, na hierarquia traduzida no princípio da unidade de comando, na estrutura piramidal do poder, nas rotinas rígidas, no controle passo a passo dos processos administrativos, em uma burocracia estatal formada por administradores profissionais especialmente recrutados e treinados, que respondem de forma neutra aos políticos. (BRESSER-PEREIRA, 1998, p. 9).

Além disso, a partir do estímulo e propagação da industrialização no território nacional, teve como resultado o surgimento dos empregos por méritos profissionais e o acesso às carreiras públicas por meio dos concursos.

Entretanto, devido à alta complexidade e ao controle excessivo na execução dos processos burocráticos, esse modo de gestão acabou tendo como resultado o engessamento dos procedimentos tornando-os ineficientes e de difícil consumação, já que a execução do serviço começa a ter menos importância do que os procedimentos. Com isso, o Estado acaba colocando-se como prioridade e perde a sua principal função que são os oferecimentos de serviços ao povo.

Embora tenha valorizado mecanismos, principalmente pela estruturação dos governos, a administração burocrática mostrou-se lenta e onerosa, criando assim o modelo de gestão gerencial, voltadas ao desenvolvimento tecnológico e a globalização. 


\subsection{PRÁTICAS GERENCIAIS DE GESTÃO}

A fim de alcançar um novo patamar de bem estar social, as práticas gerenciais começam a surgir a partir do final da $2^{\circ}$ Guerra, onde muitos países tiveram que recuperar a economia e modernizar indústrias, trazendo novos conceitos de gestão com abordagens mais descritivas e explicativas diferentemente dos sistemáticos da gestão burocrática.

No Brasil, ela se inicia a partir de 1970, com a reforma do aparelho do Estado com a criação de empresas públicas, autarquias e sociedades de economias mistas. No entanto, apenas com a criação do Plano Diretor da Reforma do Aparelho do Estado PDRAE em 1995 que o modelo de gestão gerencial teve maior relevância.

A gestão gerencial se caracteriza no envolvimento de gestores a partir de uma rede de relações afetivas, políticas, interpessoais, simbólicas e de poder, sendo independentes dos diferentes atores ou do contexto social dos envolvidos. Os processos sociais, culturais, afetivos, políticos e ideológicos estão diretamente ligados a tais relações e se tornam norteadores da ação gerencial e constroem alianças com a equipe e os pares.

No entender de Bresser Pereira (1998), há algumas características importantes para uma reforma gerencial, entre elas destacam-se: o controle dos resultados, a partir de indicadores de desempenhos estabelecidos nos contratos de gestão; controle contábil de custos; controle por quase mercados ou competição administrada; e controle social; a terceirização dos serviços e descentralização e desconcentração das políticas e atividades públicas.

Devido às diversas demandas organizacionais, o gestor se vê pressionado por seus subordinados. Na maioria das vezes, os interesses pessoais do gestor não estão alinhados com o que é desejado pela organização, necessitando assim que ele se posicione diante das situações conflitantes e que não sejam vistos como agentes imparciais e defensores dos interesses organizacionais. 
Seu maior desafio é que mesmo diante das limitações organizacionais e de hierarquia, cabe ao gestor ser produtivo e, a fim de que seja reconhecido pelos seus superiores e que torne sua organização mais eficiente e eficaz. Os gestores ficam sujeitos a uma "situação flutuante de poder, autonomia, conservadorismo, capacidade de inovar e de influenciar as relações entre os diferentes indivíduos que participam da vida organizacional." (DAVEL E MELLO, 2005, p.30).

Assim sendo, é possível descrever o papel do gestor gerencial como uma figura mediada entre o contexto social e as regras organizacionais, demandando além do conhecimento, a cordialidade, o formalismo, a pessoalidade e a improvisação. Desse modo, visa à obtenção dos resultados através da simplificação dos processos e da prestação de serviços públicos com qualidade.

\section{A ADMINISTRAÇÃO PÚBLICA A PARTIR DAS ATUAIS PRÁTICAS GERENCIAIS DE GESTÃO}

Tendo por base os avanços tecnológicos atuais, a administração burocrática já não atendia mais às demandas e as exigências que a sociedade civil apresentava aos governos e a nova prática gerencial na administração pública vão sendo inseridas na gestão. Para Chiavenato (2000, p.6), "a tarefa da Administração é a de interpretar os objetivos propostos pela organização e transformá-los em ação organizacional [...]", por meio dos processos de planejamento, organização, direção e controle. Assim, o procedimento de gerenciar os recursos e gerir as pessoas é único tanto na esfera pública, quanto na privada. As práticas administrativas são as mesmas, divergindo somente quanto à legislação específica, às normas internas e à cultura organizacional.

A fim de tornar uma gestão mais satisfatória, os governos foram criando medidas a fim de trazerem melhor transparência com crescimento econômico e controle orçamentário e financeiro, gerando assim melhorias na qualidade dos serviços públicos e gerando uma efetividade social, para isso assemelham-se técnicas utilizadas nas empresas privadas. 
Sabendo-se que o gestor gerencial deve agir pela impessoalidade, uma das finalidades na administração é o interesse público, assegurando assim a cobrança e participação social na fiscalização e controle das ações. Do ponto de vista jurídico, busca-se envolver a submissão dos entes, dos órgãos e dos agentes públicos perante o Estado e a sociedade.

Desse modo, a partir desta participação social, a sociedade civil se torna ativa nas resoluções de problemas do governo a partir de uma gestão participativa nas funções estatais, visando uma otimização sobre a divisão do capital fazendo que ele atenda todas as esferas sociais.

Os princípios básicos da administração pública estão consubstanciados em seis regras de observância permanente e obrigatória para o bom administrador: legalidade, moralidade, impessoalidade, razoabilidade, publicidade e eficiência. Por esses padrões é que se hão de pautar todos os atos administrativos. Constituem, por assim dizer, os fundamentos da ação administrativa, ou, por outras palavras, os sustentáculos da atividade pública. Relegá-los é desvirtuar a gestão dos negócios e olvidar o que há de mais elementar para a boa guarda e zelo dos interesses sociais. (MEIRELLES, 1999, p.81)

Além disso, nos modelos gerenciais há um processo de descentralização dos agentes hierárquicos ou de entidades da administração pública, onde a participação efetiva de organizações sociais e não governamentais é mais evidenciada, principalmente para o desenvolvimento de ações sociais eficazes às quais não eram alcançadas pelos governos.

Com a finalidade de tornar a gestão gerencial mais efetiva, que seja capaz de atender todas as demandas operacionais e os interesses sociais, promovem-se planos de carreira para valorização técnica e profissional do servidor e também oferecendo capacitação a fim de que desenvolvam políticas públicas capazes de garantir o desenvolvimento social e econômico.

A fim de gerar um marco regulatório, com foco em fiscalizar e disciplinar as gestões contábeis e orçamentárias temos as agências reguladoras. A partir dos novos paradigmas, a partir do ano 2000 essa fiscalização de controle econômico e financeiro 
são ampliadas com a Lei de Responsabilidade Fiscal, onde se foram criadas metas fiscais e responsabilidades objetivas aos gestores públicos, tanto nas entidades e organizações públicas da administração direta e indireta.

Utilizando ferramentas das instituições privadas, o foco principal passa a ser a qualidade da prestação do serviço público direcionado à satisfação de todos os cidadãos, com enfoque na produtividade. Além disso, as avaliações de desempenho e o seu monitoramento proporcionam a elevação do controle, entrando assim em total contradição com um dos princípios norteadores gerenciais que incentiva a autonomia e flexibilização do gestor de acordo com o contexto social em que está inserido .

A maior dificuldade para o gestor é fazer com que as novas práticas gerenciais viabilizem efetivamente as exigências do cidadão. Ainda há muitas resistências quanto às essas mudanças estruturais, pois é possível observar que as decisões ainda são tomadas por um pequeno grupo.

Pode-se definir a administração pública brasileira nos seguintes aspectos: o burocratismo, a ingerência dos agentes políticos nas decisões da instituição, a repulsão à inovação, e a descontinuidade da gestão, ocasionando a não conclusão de projetos de curto prazo que possuam interesses divergentes e gestores nem sempre preparados para o desempenho de suas atribuições (PIRES; MACEDO, 2006).

Assim sendo, a atual administração pública brasileira ainda é marcada por fortes influências das práticas patrimonialistas e burocráticas, no entanto as práticas gerenciais são as mais utilizadas nos órgãos públicos. Com uma administração voltada para a satisfação do cidadão e obtenção de efetivos resultados à sociedade, os princípios de gerencialismo são os mais eficientes para a contemporaneidade, no entanto ainda levará alguns anos para ser assimilado por completo, exigindo assim mais capacitação e conscientização aos servidores sobre este modelo de gestão. 


\section{CONCLUSÃO}

A corrupção e a presença de troca de favores entre o público e o privado revelam que nos dias atuais há uma fusão do modelo de gestão patrimonial, assim como os princípios de profissionalização e formalismo da gestão burocrática.

Baseado pela legitimidade é possível verificar que nos dias atuais, a gestão pública gerencial mantém ainda mais forte a participação da sociedade, visando à procura da obtenção de resultados efetivos à sociedade.

Diferentemente dos modelos de heranças patrimonialistas e o interesse administrativo do Estado da gestão burocrática, na gestão gerencial não se busca analisar os procedimentos, seu foco é voltado para o cidadão e suas práticas sociais. Sabemos que esse modelo de gestão ainda está muito aquém do desejado, pois é possível verificar que há uma junção de elementos culturais diferentes, em um só contexto, mas ainda com algumas enraizadas em modelos de gestões patrimoniais e burocráticas.

A fim de enfrentar a mudança de paradigma do cenário público e as rápidas evoluções do mundo globalizado, um gestor público deve ser atento e ser flexível, sendo necessária empiricamente a criação de estratégias onde transformem conhecimentos dos gestores em ação e uma efetiva participação de representantes da sociedade que tenha consonância com os interesses coletivos.

Assim sendo, mesmo com tantos anos de desenvolvimento, o modelo de gestão gerencial ainda está em constante construção, cabe ao administrador público o desafio de inovação, potencializando os resultados obtidos e no equilíbrio dos procedimentos patrimonialistas e burocráticos com o gerencial.

\section{REFERÊNCIAS BIBLIOGRÁFICAS}

BRASIL. Constituição da República Federativa do Brasil. Brasília, DF: Senado, 1988.

Disponível em: 
http://www.planalto.gov.br/ccivil_03/constituicao/constituicaocompilado.htm Acesso em: 18 dez. 2020

BRESSER PEREIRA, L. C. Uma reforma Gerencial da Administração Pública no Brasil. Revista do Serviço Público, Brasília, a. 49, n. 1, janeiro-março 1998.

BRESSER PEREIRA, Luiz Carlos. Gestão do setor público: estratégia e estrutura para um novo Estado. In: BRESSER PEREIRA, L. C.; SPINK, P. (Org.). Reforma do Estado e administração pública gerencial. 2. ed. Rio de Janeiro: FGV, 1998.

CHIAVENATO, Idalberto. Introdução à teoria geral da administração. 6. ed. Rio de Janeiro: Campus, 2000.

DAVEL, E; MELO M. C. L. Singularidades e transformações no trabalho dos gerentes. In DAVEL, E. (Org.) e MELO M. C. L. (Org.); Gerência em ação. Rio de Janeiro: FGV, 2005.

HOLANDA, Sérgio Buarque de. Raízes do Brasil. 4. ed. [S.I.]: Editora da Universidade, 1963.

MEIRELLES, Hely Lopes. Direito administrativo brasileiro. 24 ed. São Paulo: Malheiros, 1999. p. 81-83.

PIRES, José Calixto de Souza; MACÊDO, Kátia Barbosa. Cultura organizacional em organizações públicas no Brasil. Revista de Administração Pública, Rio de Janeiro, v.40, n.1, p.81-105, jan./fev. 2006. Disponível em: <http://bibliotecadigital.fgv.br/ojs/index.php/rap/article/view/6805/5387>>. Acesso em: 17 dez. 2020

TORRES, Marcelo Douglas de Figueiredo. A evolução da administração pública brasileira. Estado, democracia e administração pública no Brasil. Rio de Janeiro: Ed. FGV, 2004, p.145.

Enviado: Dezembro, 2020. 
Aprovado: Dezembro, 2020. 